\title{
Investigation of the Dependence of Ambipolarity on Channel Thickness for TMDC Based Field Effect Transistors
}

\author{
Merve ACAR ${ }^{1} \oplus$, Mehmet ERTUĞRUL ${ }^{2 *}(\mathbb{D}$ \\ Department of Electrical Electronics Engineering, Engineering Faculty, Ataturk University, 25240 Erzurum, \\ Turkey
}

Geliş / Received: 20/04/2021, Kabul / Accepted: 18/05/2021

\begin{abstract}
This paper mainly focused on one of the recent attractive electronic devices which is the ambipolar field-effect transistor. Ambipolarity has become important for many applications in recent years. Many factors that cause ambipolarity have been reported in the literature. However, the causes of ambipolarity have not been fully investigated so far. In this study, the degree of ambipolarity was determined as a function of the channel thickness for the $\mathrm{WS}_{2}$ FET device. For the $\mathrm{WS}_{2}$ FET device, the ambipolarity starts from a few layers of channel thickness, and then as the thickness increases, the ambipolarity begins to decrease again. It has been observed that as the thickness increases, the degree of ambipolarity approaches zero. The fact that the degree of ambipolarity approaches zero indicates that the $\mathrm{WS}_{2}$ channel exhibits natural $\mathrm{n}$-type behavior and the ambipolarity effect disappears.
\end{abstract}

Keywords: field effect transistor, ambipolarity, TMDC.

\section{TMDC Tabanlı Alan Etkili Transistörlerde Ambipolaritenin Kanal Kalınlığına Bağımlılığının} Araştırılması

\section{Öz}

Bu çalışmada ağırlıklı olarak güncel ambipolar alan etkili transistor üzerinde duruldu. Ambipolarite, son yıllarda birçok uygulama için önemli hale geldi. Literatürde ambipolariteye neden olan birçok faktör bildirilmiştir. Bununla birlikte, ambipolaritenin nedenleri literatürde tam olarak araştırılmamıştır. Bu çalışmada, ambipolarite derecesi, $W_{2}$ FET cihazı için kanal kalınlığının bir fonksiyonu olarak belirlenmiştir. Kalınlık arttıkça ambipolarite derecesinin sıfira yaklaştığı görülmüştür. Ambipolarite derecesinin sıfira yaklaşması, WS 2 kanalının doğal n-tipi davranış sergilediğini ve ambipolarite etkisinin ortadan kalktığını gösterir.

Anahtar Kelimeler: alan etkili transistor, ambipolarite, TMDC.

\section{Introduction}

According to the switching characteristic and the dominant charge carriers in semiconductors, the polarity of transistors can be categorized as unipolar (full-dominant p-type or electrondominant n-type) or bipolar (ambipolar) (holes and electron together) (Van Berkel \& Powell, 1987). The behavior of unipolar and ambipolar transmitters is given in Figure 1. The simultaneous transfer of electrons and holes in ambipolar materials and devices, together with p-type and n-type properties in a single device, makes them useful in many different applications. In the last few years, various bipolar materials such as organic materials (Ni et al.,

*Corresponding Author: ertugrul@ atauni.edu.tr 
2019), carbon nanotubes (Gomulya et al., 2015), two-dimensional (2D) (Baugher, Churchill, Yang, \& Jarillo-Herrero, 2014) and perovskite materials (Li et al., 2015) have been investigated. Various device architectures (El Gemayel et al., 2014; Gao, Zhang, Kong, Chen, \& Jiang, 2015) have been created for device applications that perform ambipolar transmission, such as solar cells (Das, Pandey, Thomas, \& Roy, 2019), logic devices (T. Liu et al., 2018), neuromorphic devices (Ren et al., 2018), light emitting transistors (LETs) (J. Liu et al., 2015), and gas sensors (Wannebroucq et al., 2018). Ambipolar materials and devices have been studied for their intrinsic properties, which can greatly increase the electrical performance of the devices by reducing the complexity of fabrication (Wang et al., 2018), as well as generating new electrical and optoelectronic phenomena.
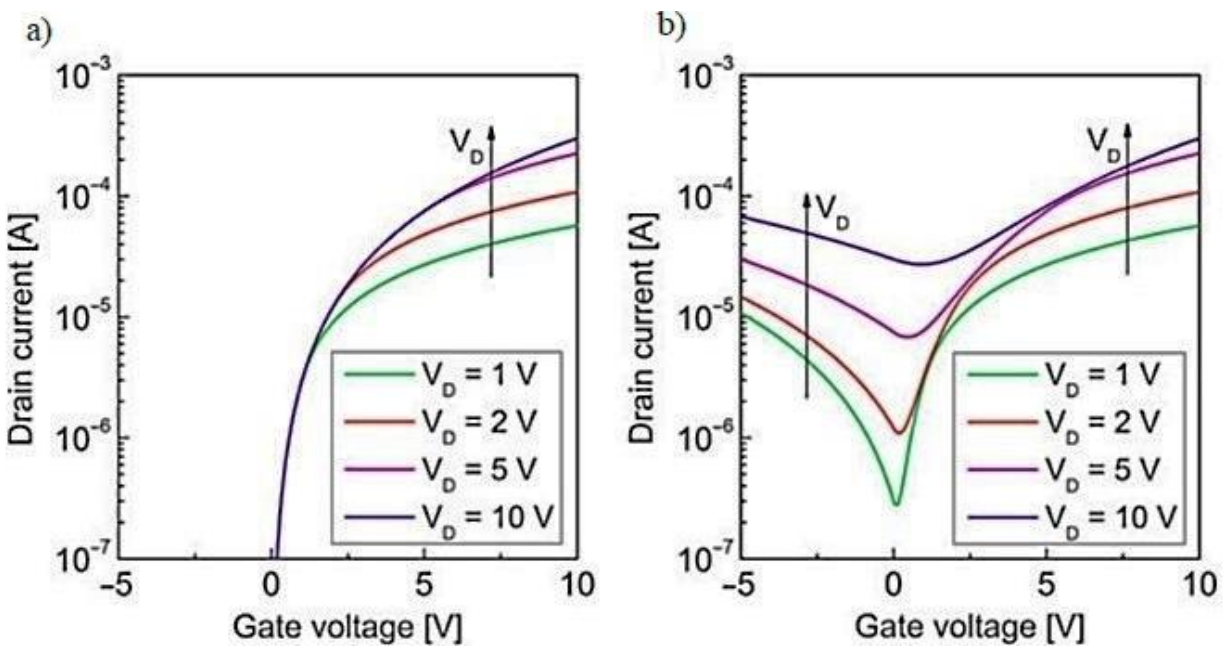

Figure 1. Comparison of the current/voltage characteristics of an unipolar (a) and an ambipolar (b) transistor (Chen et al., 2012).

In ambipolar transistors, $\mathrm{p}$ - and n-type electrical performance has seen in a single device. For this reason, it has attracted the attention of researchers in device fields (Bisri, Piliego, Gao, \& Loi, 2014). Ambipolar transistors carrying both charges further simplify the construction of metal oxide semiconductor devices. In addition, devices that exhibit ambipolar behavior show unipolar behavior due to the return of the material to its natural state at high voltages (Acar, Mobtakeri, Efeoğlu, Ertuğrul, \& Gür, 2020).

The ambipolar behavior in transistors is attributed to various reasons in the literature. These are;

It has been shown that by changing the thickness of the $\mathrm{WS}_{2}$ semiconductor channel, the polarity can be changed and thus the channel thickness has an effect on the ambipolarity (Radisavljevic, Radenovic, Brivio, Giacometti, \& Kis, 2011; Pudasaini et al., 2018; Wang et al., 2018).

- The formation of Tungsten oxide in the $\mathrm{WS}_{2}$ structure has a p-type doping effect, which causes to show ambipolar behavior.

- One of the behaviors of ambipolarity is charge traps due to several reasons such as defects and gaps in the semiconductor layer (Ren et al., 2019). 
- It is reported in the literature that the sulfur content causes ambipolarity. $\mathrm{WS}_{2}$ has shown n-type characteristics as the $\mathrm{S} / \mathrm{W}$ ratio approaches 2 . On the other hand, it shows p-type behavior as the sulfur ratio moves away from 2 to 1 . Due to the sulfur deficiency in the material, tungsten bonds can be formed with the oxide layer on the surface of the films. This situation is thought to be another reason for the observed ambipolarity.

- Due to the water vapor accumulating on the surface, a layer of positive charges $\left(\mathrm{H}^{+}\right)$ may formed on the surface of the film. This layer causes some of the free electrons in the thin film to be trapped. This situation is thought to be another reason of ambipolarity.

In the literature, it has been suggested by theoretical models that $\mathrm{WS}_{2}$ based transistors may play a role in n-type, p-type or ambipolar behavior due to various conditions. (Risteska et al., 2012). An n-type transistor with ambipolar behavior can have four regions and those regions are theoretically modeled in the literature (Risteska et al 2012). One of the regions where the carrier charges are electrons and holes is shown ambipolar behavior. The drain current equation for this region is given as follows (Chen et al., 2012):

$$
I_{D}=\frac{W}{2 L} C_{G}\left[\mu_{e}\left(V_{G}-V_{T N}\right)^{2}+\mu_{p}\left(V_{D}-\left(V_{G}-V_{T P}\right)\right)^{2}\right]
$$

In this equation; $I_{D}$ is the drain current, $W$ is the channel width, $L$ is the length, $C_{G}$ is the gate capacitance, $\mu_{\mathrm{n}}$ is the electron mobility, $\mu_{\mathrm{p}}$ is the hole mobility, $\mathrm{V}_{\mathrm{D}}$ is the drain voltage, $\mathrm{V}_{\mathrm{G}}$ is the gate voltage, $\mathrm{V}_{\mathrm{TN}}$ is the electrons' threshold voltage.

Experimental studies have shown that electron and hole mobility depend on thickness (Kim et al., 2016; Rawat, Jena, \& De Sarkar, 2018; Kang, Jeon, \& Kim, 2020). As can be seen from the Figure 2, when thickness increases from mono layer to 6 layers, electron mobility increases from 10 to $18 \mathrm{~cm}^{2} / \mathrm{Vs}$ for $\mathrm{MoS}_{2}$ based FET device. The study suggests that the increase in mobility may be associated with the thickness dependence of the $\mathrm{MoS}_{2}$ device's contact resistance and dielectric constant (Kim et al., 2016).

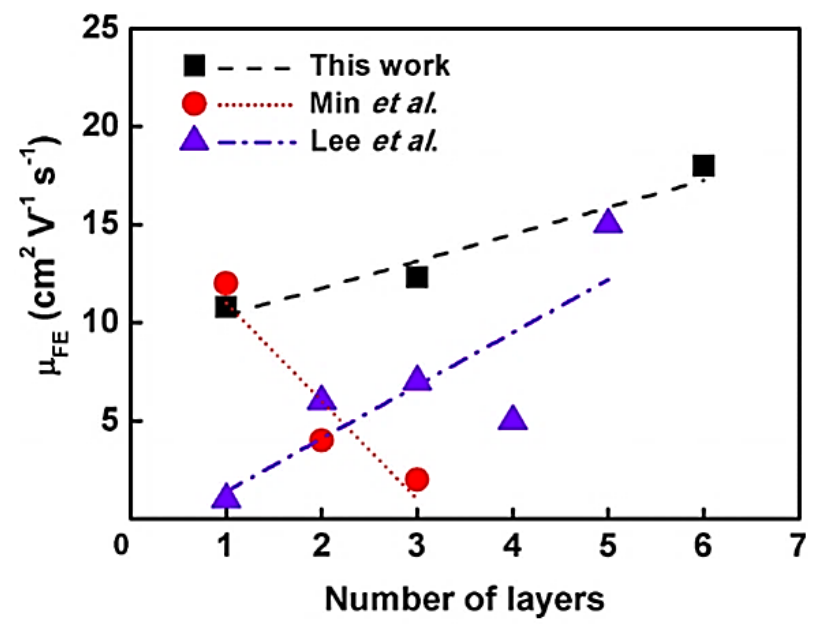

Figure 2. Change of electron mobility with layer number in $\mathrm{MoS}_{2}$ FET device (Kim, et al. 2016).

Electron and hole mobility may depend on several factors besides thickness such as temperature, gate voltage (Ovchinnikov, Allain, Huang, Dumcenco, \& Kis, 2014). In the literature, the dependence of ambipolarity on thickness has been shown, but the degree of 
ambipolarity with thickness has not been investigated. This study is aimed to contribute to the literature by examining the dependence of the degree of ambipolarity on thickness.

In a study in the literature, the degree of ambipolarity is given by the following equation (Senanayak, Ashar, Kanimozhi, Patil, \& Narayan, 2015).

$$
D=\frac{\mu_{p}}{\mu_{e}}
$$

Here $\mu_{\mathrm{p}}$ and $\mu_{\mathrm{e}}$ are hole and electron mobility, respectively. Since $\mathrm{WS}_{2}$ is naturally an n-type semiconductor, the $\mathrm{D}$ value decreases as the n-type natural behavior of the $\mathrm{WS}_{2}$ material begins to dominate and reaches a constant value. In the literature, devices produced from TDMS materials show a p-type behavior as they move towards a monolayer. On the other hand, it has been shown that as the number of layers or thickness increases, the material evolves from the p-type behavior first to the ambipolar behavior and then to the n-type behavior for $\mathrm{MoS}_{2}$, which is the natural behavior of the material (Figure 3) (Rani et al., 2019) .

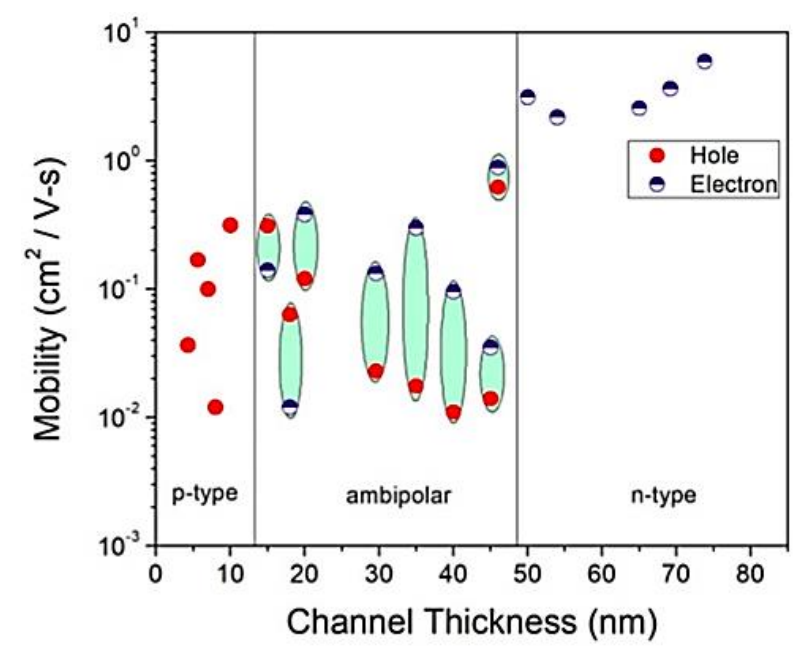

Figure 3. Field-effect mobility of electrons and holes vs. channel thickness for $\mathrm{MoTe}_{2} \mathrm{FETs}$ (Rani et al., 2019).

However, the dependence of the degree of ambipolarity on thickness in the ambipolar region has not been investigated in the literature. In this study, thickness dependence of the degree of ambipolarity was investigated for 4 different thicknesses between 8 and $30 \mathrm{~nm}$. It has been observed that the results we have obtained show the same trend with the literature in general.

\section{Material and Methods}

In the literature, TMDC materials are mostly grown by CVD techniques (Zhang et al., 2019). However, TDMC films grown with CVD are not large scale but in the form of flakes. For this reason, it is either very difficult or very expensive to fabricate transistors at a scale applicable to the technology with thin-film TMDCs growth by the CVD technique. In addition, the uniformity of flake-shaped TMDC film growth with CVD is also problematic. For all these reasons, the sputtering technique that allows large-scale TMDC film growth was used in this study. In order to obtain $\mathrm{WS}_{2}$ thin films in a single step, growth was performed on $\mathrm{Si} / \mathrm{SiO}_{2}$ substrates in Argon environment using $\mathrm{WS}_{2}$ target. The growth parameters that affect the $\mathrm{WS}_{2}$ channel thickness with sputtering as shown by our previous article (Acar et al., 2020) and that may affect the ambipolarity behavior other than the thickness are given in the Table 1. 
Table 1. Parameters of $\mathrm{WS}_{2}$ thin films grown by sputtering technique.

\begin{tabular}{|l|l|}
\hline Target Purity $\left(\mathrm{WS}_{2}\right)(\%)$ & 99.8 \\
\hline Power $(\mathrm{W})$ & 120 \\
\hline Base Pressure (Torr) & $10^{-7}$ \\
\hline Sputtering Pressure (mTorr) & 20 \\
\hline Growth Ambient & $\mathrm{Ar}(220 \mathrm{sscm})$ \\
\hline Growth Time (Second) & $1,5,10,30$ \\
\hline Growth Temperature $\left({ }^{\circ} \mathrm{C}\right)$ & 300 \\
\hline Substrate-Target Distance $(\mathrm{cm})$ & 7 \\
\hline Substrate Rotation Speed $(\mathrm{rot} / \mathrm{s})$ & $1 / 20$ \\
\hline
\end{tabular}

It was observed from the samples obtained by sputtering that as the growth time increased, $\mathrm{WS}_{2}$ nano-walls were formed in the structure. FESEM image of one of the grown samples is given in Figure 4.

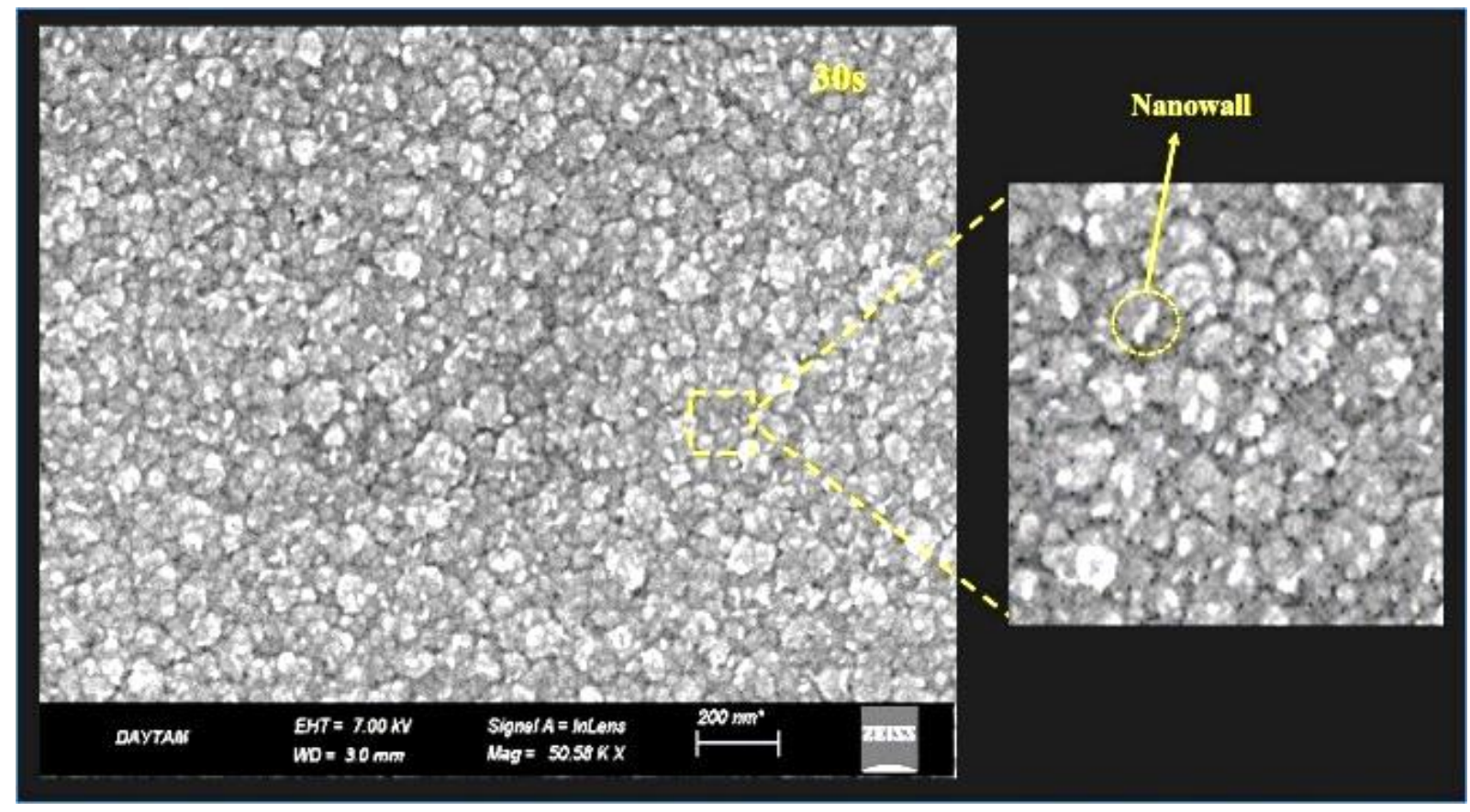

Figure 4. FESEM image of a $\mathrm{WS}_{2}$ film.

After the samples were obtained, device fabrication was started with the lithography process. The mask was first designed for fabrication. The optical lithography technique has been used to create the contacts. The device is formed by metal evaporation and lift-off steps. In order to remove the residual residues on the device and to improve the contacts, annealing was performed and the device was made ready for measurement. In this section, mask design, lithography steps, metal coating, lift-off and annealing steps are explained in detail in our previous study (Acar et al., 2020).

After the device fabrication stage, electrical measurements of the devices were carried out with the help of the homemade system (Figure 5) and software (Figure 6). 


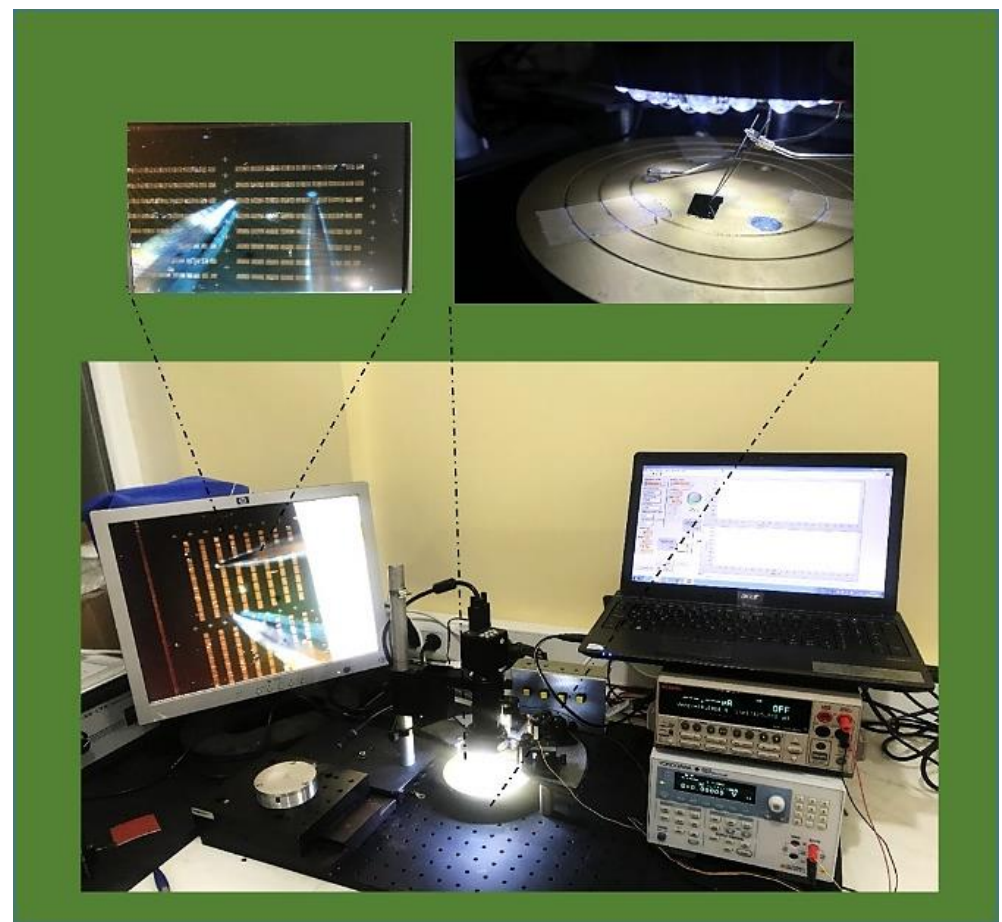

Figure 5. Homemade electrical properties measurement system.

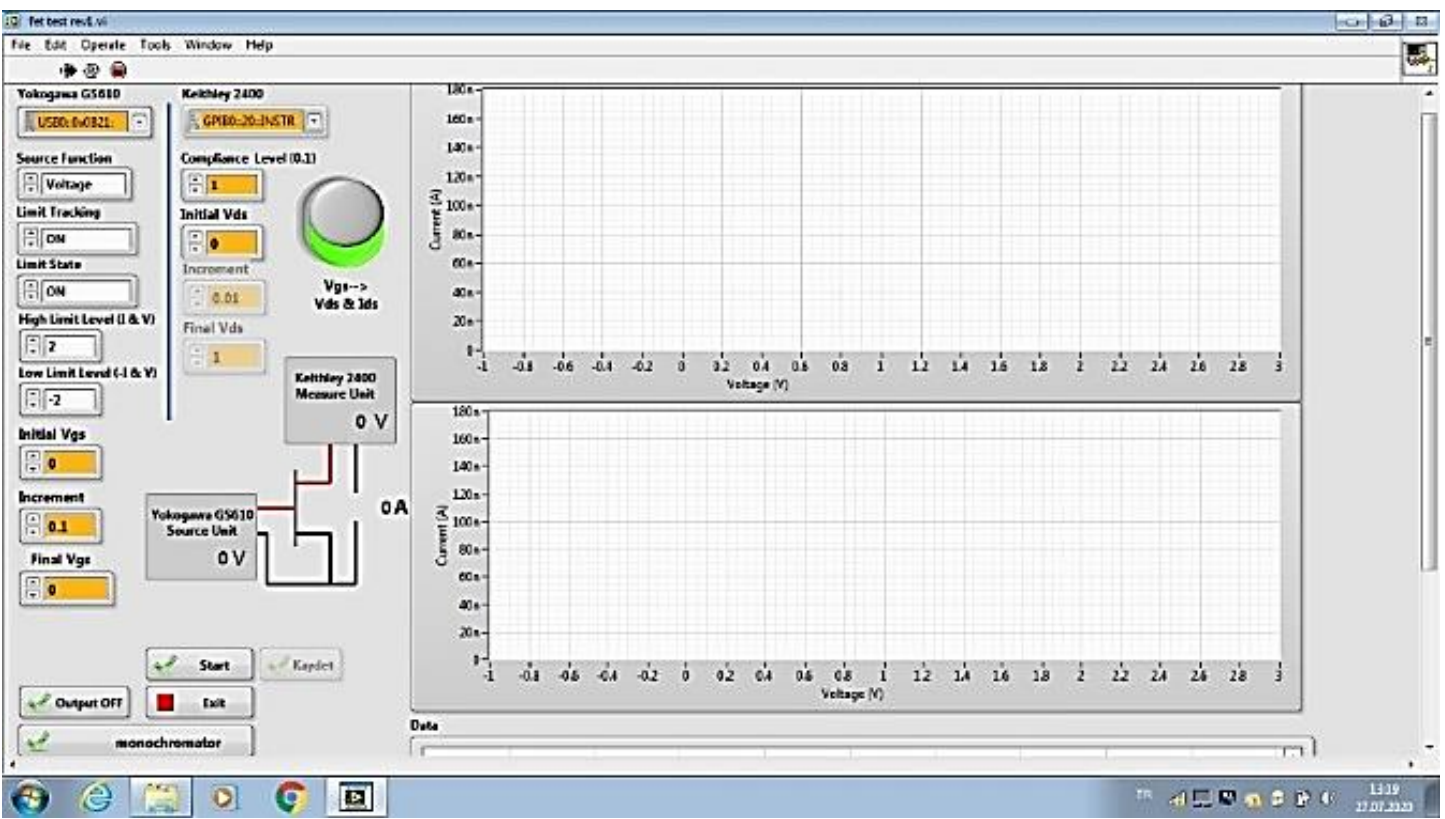

Figure 6. Homemade software for the electrical measurements.

\section{Resarch Findings}

Carrier mobility is expressed as the average charge carrier rate per applied electric field. The carrier mobility $(\mu)$ is calculated using equations given below by subtracting the transconductance (transfer conductance $(\mathrm{gm})$ ) from the slope of the region where the $I_{\mathrm{ds}}-V_{\mathrm{gs}}$ curve changes linearly.

$$
g_{m=\frac{\partial I_{d s}}{\partial V_{g s}}}
$$




$$
\mu=\frac{L}{W \times V_{d s} \times C_{i}} \times \frac{d I_{d s}}{d V_{g s}}
$$

Here; L, Channel length; $\mathrm{W}$, Channel width; $\mathrm{C}_{\mathrm{i}}, \mathrm{SiO}_{2}$ dielectric capacitance, $\varepsilon_{0}$, the dielectric constant for vacuum; $\varepsilon_{\mathrm{r}}$ is the relative dielectric constant of $\mathrm{SiO}_{2} ; \mathrm{d}$, Thickness of the insulating layer $\mathrm{SiO}_{2} ; \mathrm{V}_{\mathrm{ds}}$ is the drain-source voltage. Table 2 shows mobility values for $\mathrm{WS}_{2}$ films that grow at different times.

Table 2. Hole and electron mobility values obtained from $\mathrm{I}_{\mathrm{ds}}-\mathrm{V}_{\mathrm{gs}}$ curves grown at different times.

\begin{tabular}{|c|c|c|}
\hline $\begin{array}{c}\text { Time } \\
(\mathbf{s})\end{array}$ & $\begin{array}{c}\mathbf{p}_{\boldsymbol{\mu}} \\
\left(\mathbf{c m}^{2} / \mathbf{V s}\right)\end{array}$ & $\begin{array}{c}\mathbf{n}_{\boldsymbol{\mu}} \\
\left(\mathbf{c m}^{2} / \mathbf{V s}\right)\end{array}$ \\
\hline 1 & 0,002 & 0,0002 \\
\hline 5 & 0,235 & 0,27 \\
\hline 10 & 17,6 & 5,3 \\
\hline 30 & 301,6 & 295 \\
\hline
\end{tabular}

Since the growth processes are carried out at different times, the thicknesses of the samples were obtained with the help of an Atomic Force Microscope (AFM). However, the measurement could not be taken with AFM for growth 1s time. Therefore, a calibration curve was drawn to find the thickness for $1 \mathrm{~s}$ growth. For the calibration curve, values of known thickness and coating time are used. Thus, thickness for 1s growth film is obtained from this curve.

As expected, the thickness of $\mathrm{WS}_{2}$ films is in a linear relationship with the growth time. Using this relationship, the thicknesses of $\mathrm{WS}_{2}$ films were obtained as 8.8, 11.7, 15.3 and $29.9 \mathrm{~nm}$, for growth times of $1,5,10$ and $30 \mathrm{~s}$, respectively. Table 3 shows the values of the degree of ambipolarity according to the thickness.

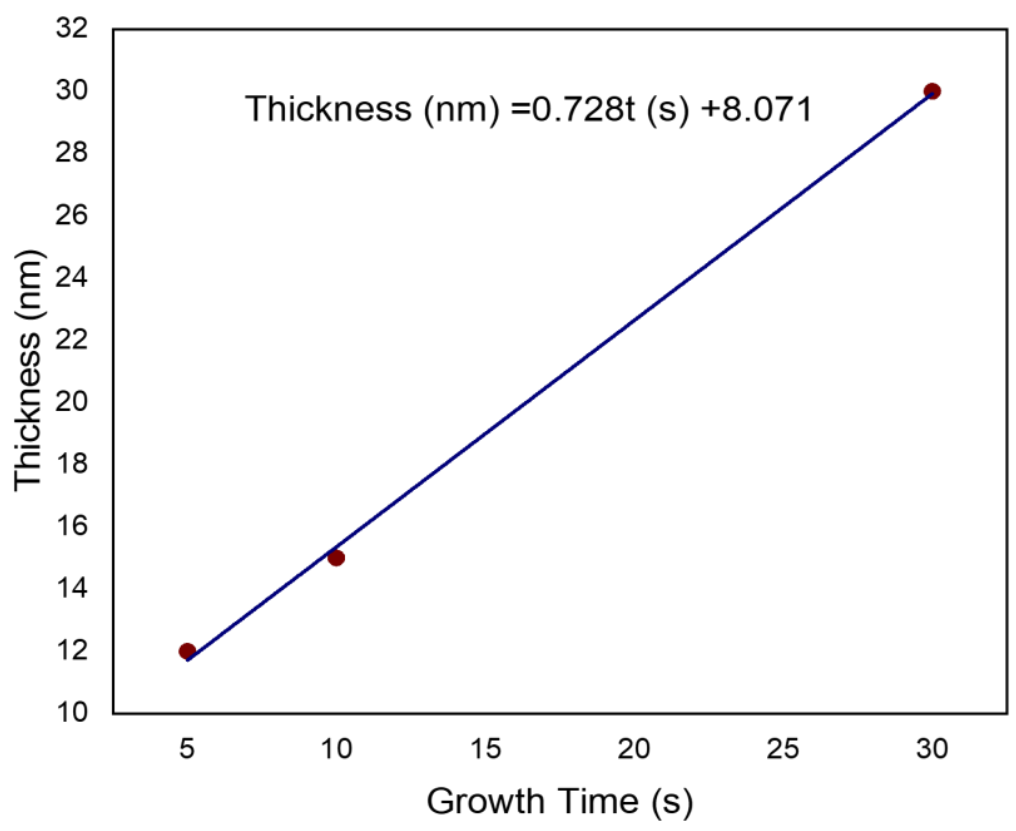

Figure 7. Thickness-Growth time graph. 
The variation of the degree of ambipolarity depending on the $\mathrm{WS}_{2}$ film thickness has been plotted using the values in Table 3 and shown in Figure 8. Estimated p-type, ambipolar and ntype regions are given in Figure 9.

Table 3. Ambipolarity degree versus $\mathrm{WS}_{2}$ film thickness (Thickness of the Monolayer $\mathrm{WS}_{2}$ is about $0.618 \mathrm{~nm}$ )

\begin{tabular}{|c|c|c|c|c|c|}
\hline $\begin{array}{l}\text { Thickness } \\
\text { (nm) }\end{array}$ & $\begin{array}{c}\text { Hole } \\
\text { Mobility } \\
\mu_{\mathbf{p}} \\
\left(\mathrm{cm}^{2} / \mathrm{Vs}\right)\end{array}$ & $\begin{array}{c}\text { Electron } \\
\text { Mobility } \\
\mu_{\mathrm{n}} \\
\left(\mathrm{cm}^{2} / \mathrm{Vs}\right)\end{array}$ & $\begin{array}{c}\text { Ambipolarity } \\
\text { Degree (D) } \\
\left(\mu_{\mathrm{p}} / \mu_{\mathrm{n}}\right)\end{array}$ & Reference & $\begin{array}{l}\text { Growth } \\
\text { method }\end{array}$ \\
\hline 8,8 & 0,002 & 0,0002 & 10 & \multirow{4}{*}{ (Acar et al., 2020) } & \multirow{4}{*}{ Sputtering } \\
\hline 11,7 & 0,235 & 0,27 & $\mathbf{0 , 8 5}$ & & \\
\hline 15,3 & 17,6 & 5,3 & 3,32 & & \\
\hline 29,9 & 301,6 & 295 & 1,02 & & \\
\hline 0,618 & 116 & 540 & 0,215 & Krymowski (2015) & Theoretical \\
\hline 0,618 & 43 & 44 & 0,98 & $\begin{array}{l}\text { (Jo, Ubrig, Berger, } \\
\text { Kuzmenko, } \& \\
\text { Morpurgo, 2014) }\end{array}$ & $\begin{array}{l}\text { Mechanically } \\
\text { exfoliation }\end{array}$ \\
\hline 0,8 & 0,28 & 0,46 & 0,61 & (Zhang et al., 2013) & CVD \\
\hline 12 & 110 & 214 & 0,51 & $\begin{array}{l}\text { (Lee, Oh, Kim, \& } \\
\text { Kim, 2020) }\end{array}$ & $\begin{array}{l}\text { Mechanically } \\
\text { exfoliation }\end{array}$ \\
\hline Bulk & 50 & 200 & 0,25 & $\begin{array}{l}\text { (Roy \& } \quad \text { Bermel, } \\
2018)\end{array}$ & \\
\hline
\end{tabular}

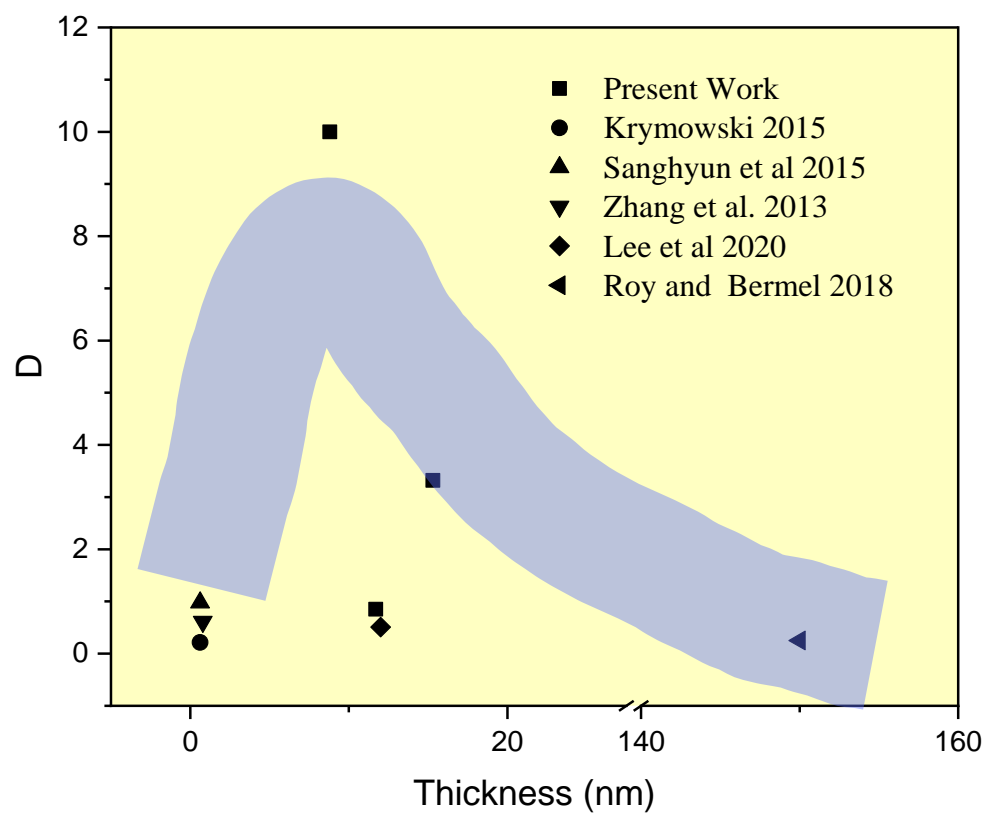

Figure 8. Variation of the degree of ambipolarity with $\mathrm{WS}_{2}$ film thickness. 


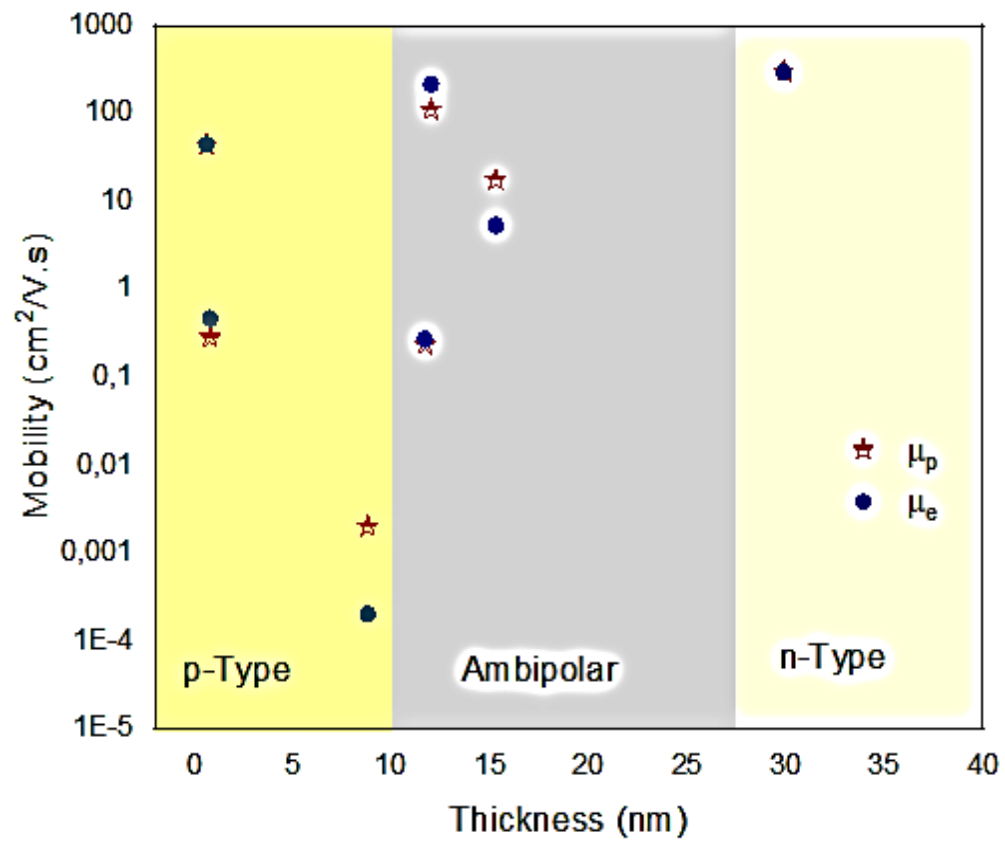

Figure 9. Estimated p-type, ambipolar and n-type regions for sputtered growth $\mathrm{WS}_{2}$ FET

\section{Discussion}

Electron and hole mobility for the $\mathrm{WS}_{2}$ films differ in the literature depending on many factors such as growth method, thickness, growth and annealing temperature, gate voltage, etc. In the literature, it has been reported that the electron mobility of $\mathrm{WS}_{2}$ monolayer films ranged from 0,01 to $234\left(\mathrm{~cm}^{2} / \mathrm{V} . \mathrm{s}\right)$ while the electron mobility of bulk $\mathrm{WS}_{2}$ is $205\left(\mathrm{~cm}^{2} / \mathrm{Vs}\right)$. On the other hand, bandgaps of monolayer and bulk $\mathrm{WS}_{2}$ are 1.7 and $1.2 \mathrm{eV}$, respectively [Boeckl and Jagadish 2016]. In addition to these, the number of studies in the literature investigating the dependence of electron and hole mobility on thickness is not sufficient to give statistically significant results. Therefore, it is difficult to compare the results obtained in this study in the literature. However, when the results in the literature were compared with this study, it was seen that they showed similar behavior. For this reason, it has been tried to evaluate the current study together with the few studies in the literature.

Devices showing ambipolarity behavior have become important for many applications in recent years. Explaining the reasons of ambipolarity behavior is important for understanding the ambipolar devices. In addition, understanding this phenomenon makes it easier to control whether ambipolar devices can behave $\mathrm{p}$ or n-type. Many factors affecting ambipolarity have been reported in the literature. In this study, the dependence of the $\mathrm{WS}_{2}$ FET device's ambipolarity on the $\mathrm{WS}_{2}$ film thickness was investigated and it has shown that, similar to the literature, the $\mathrm{WS}_{2}$ films with a few layer thicknesses showed p-type behavior. It has been observed that as the thickness increases monolayer to multilayer, the $\mathrm{WS}_{2}$ FET device shifts their ambipolar behavior. It has been determined that as the thickness of the $\mathrm{WS}_{2}$ thin-film increases from multilayer $(20-30 \mathrm{~nm})$ to the bulk structure, it turns from ambipolar behavior to $\mathrm{n}$-type behavior again and then the $\mathrm{WS}_{2}$ material completely returns to its natural or bulk state and exhibits n-type behavior. Ambipolarity depends on many factors such as $\mathrm{WS}_{2}$ thickness, gate voltage, annealing temperature, W/S ratio, thin-film growth technique, crystal defects, etc. In this study, since the sputtering technique is used to grow the $\mathrm{WS}_{2}$ films, film growth 
parameters for the sputtering technique also affect the ambipolarity behavior. In addition to this study, the effects of these parameters on ambipolarity have not been examined in the literature. These will be focused on in future studies.

Ambipolar FET devices are relatively new and important due to their many application potentials. However, there are not enough studies in the literature, especially regarding the dependence of ambipolarity on channel thickness. A complete and clear presentation of ambipolar behavior will make an important contribution to the literature in this regard. In this study, results that can contribute to the literature were obtained for $\mathrm{WS}_{2}$ devices grown by the sputtering method. However, new and further studies should be done to better understand ambipolarity and to validate the results obtained in this study.

Acknowledgments: The authors thank Prof. Dr. Emre Gür for his guidance and Soheil Mobtakeri for providing $\mathrm{WS}_{2}$ films.

\section{References}

Acar, M., Mobtakeri, S., Efeoğlu, H., Ertuğrul, M., \& Gür, E. (2020). Single-step, large-area, variable thickness sputtered WS2 film-based field effect transistors. Ceramics International, 46(17), 26854-26860.

Acar, M. 2020 " Design and Fabrication of Nanodevices Using Two Dimensional Materials", Dokrora, Atatürk Üniversitesi Fen Bilimleri Enstitüsü, Erzurum, 102.

Baugher, B. W., Churchill, H. O., Yang, Y., \& Jarillo-Herrero, P. (2014). Optoelectronic devices based on electrically tunable $\mathrm{p}-\mathrm{n}$ diodes in a monolayer dichalcogenide. Nature nanotechnology, 9(4), 262-267.

Bisri, S. Z., Piliego, C., Gao, J., \& Loi, M. A. (2014). Outlook and emerging semiconducting materials for ambipolar transistors. Advanced materials, 26(8), 1176-1199.

Chen J., Cranton W., Fihn M. (2012). “ Handbook of Visual Display Technology/ Organic Ambipolar Transistors and Circuits". DOI 10.1007/978-3-540-79567-4

Das, S., Pandey, D., Thomas, J., \& Roy, T. (2019). 2D Materials: The Role of Graphene and Other 2D Materials in Solar Photovoltaics (Adv. Mater. 1/2019). Advanced materials, 31(1), 1970006.

El Gemayel, M., Haar, S., Liscio, F., Schlierf, A., Melinte, G., Milita, S., . . Samorì, P. (2014). Leveraging the Ambipolar Transport in Polymeric Field-Effect Transistors via Blending with Liquid-Phase Exfoliated Graphene. Advanced materials, 26(28), 4814-4819.

Gao, D., Zhang, X., Kong, X., Chen, Y., \& Jiang, J. (2015). (TFPP) Eu [Pc (OPh) 8] Eu [Pc $(\mathrm{OPh})$ 8]/CuPc two-component bilayer heterojunction-based organic transistors with high ambipolar performance. Acs Applied Materials \& Interfaces, 7(4), 2486-2493.

Gomulya, W., Rios, J. M. S., Derenskyi, V., Bisri, S. Z., Jung, S., Fritsch, M., . . Loi, M. A. (2015). Effect of temperature on the selection of semiconducting single walled carbon nanotubes using Poly (3-dodecylthiophene-2, 5-diyl). Carbon, 84, 66-73. 
J. Boeckl and Chennupati Jagadish (Eds.), 2D Materials-Academic Press (2016) p.223

Jo, S., Ubrig, N., Berger, H., Kuzmenko, A. B., \& Morpurgo, A. F. (2014). Mono-and bilayer WS2 light-emitting transistors. Nano letters, 14(4), 2019-2025.

Kang, Y., Jeon, D., \& Kim, T. (2020). Direct Observation of the Thickness-Dependent Dielectric Response of MoS2 and WSe2. The Journal of Physical Chemistry C, 124(33), 1831618320.

Kim, J. H., Kim, T. H., Lee, H., Park, Y. R., Choi, W., \& Lee, C. J. (2016). Thickness-dependent electron mobility of single and few-layer MoS2 thin-film transistors. Aip Advances, 6(6), 065106.

Krymowski K. E., (2015). " Electronic Mobilities of Two-Dimensional Transition Metal Dichalcogenides" Ph. D. Materials Science and Engineering. The Ohio State University.

Lee, G., Oh, S., Kim, J., \& Kim, J. (2020). Ambipolar Charge Transport in Two-Dimensional WS2 Metal-Insulator-Semiconductor and Metal-Insulator-Semiconductor Field-Effect Transistors. Acs Applied Materials \& Interfaces, 12(20), 23127-23133.

Li, F., Ma, C., Wang, H., Hu, W., Yu, W., Sheikh, A. D., \& Wu, T. (2015). Ambipolar solutionprocessed hybrid perovskite phototransistors. Nature communications, 6(1), 1-8.

Liu, J., Zhang, H., Dong, H., Meng, L., Jiang, L., Jiang, L., . . Hu, W. (2015). High mobility emissive organic semiconductor. Nature communications, 6(1), 1-8.

Liu, T., Xiang, D., Zheng, Y., Wang, Y., Wang, X., Wang, L., .. Chen, W. (2018). Nonvolatile and Programmable Photodoping in MoTe2 for Photoresist-Free Complementary Electronic Devices. Advanced materials, 30(52), 1804470.

Ni, Z., Wang, H., Zhao, Q., Zhang, J., Wei, Z., Dong, H., \& Hu, W. (2019). Ambipolar Conjugated Polymers with Ultrahigh Balanced Hole and Electron Mobility for Printed Organic Complementary Logic via a Two-Step C $\square$ H Activation Strategy. Advanced materials, 31(10), 1806010.

Ovchinnikov, D., Allain, A., Huang, Y.-S., Dumcenco, D., \& Kis, A. (2014). Electrical transport properties of single-layer WS2. Acs Nano, 8(8), 8174-8181.

Pudasaini, P. R., Oyedele, A., Zhang, C., Stanford, M. G., Cross, N., Wong, A. T., .. . Mandrus, D. G. (2018). High-performance multilayer WSe 2 field-effect transistors with carrier type control. Nano Research, 11(2), 722-730.

Radisavljevic, B., Radenovic, A., Brivio, J., Giacometti, V., \& Kis, A. (2011). Single-layer MoS 2 transistors. Nature nanotechnology, 6(3), 147-150.

Rani, A., DiCamillo, K., Khan, M. A. H., Paranjape, M., \& Zaghloul, M. E. (2019). Tuning the polarity of MoTe2 FETs by varying the channel thickness for gas-sensing applications. Sensors, 19(11), 2551.

Rawat, A., Jena, N., \& De Sarkar, A. (2018). A comprehensive study on carrier mobility and artificial photosynthetic properties in group VI B transition metal dichalcogenide monolayers. Journal of Materials Chemistry A, 6(18), 8693-8704. 
Ren, Y., Yang, J. Q., Zhou, L., Mao, J. Y., Zhang, S. R., Zhou, Y., \& Han, S. T. (2018). Gatetunable synaptic plasticity through controlled polarity of charge trapping in fullerene composites. Advanced Functional Materials, 28(50), 1805599.

Ren, Y., Yang, X., Zhou, L., Mao, J. Y., Han, S. T., \& Zhou, Y. (2019). Recent advances in ambipolar transistors for functional applications. Advanced Functional Materials, 29(40), 1902105.

Risteska, A., Chan, K.-Y., Anthopoulos, T. D., Gordijn, A., Stiebig, H., Nakamura, M., \& Knipp, D. (2012). Designing organic and inorganic ambipolar thin-film transistors and inverters: Theory and experiment. Organic Electronics, 13(12), 2816-2824.

Roy, S., \& Bermel, P. (2018). Electronic and optical properties of ultra-thin 2D tungsten disulfide for photovoltaic applications. Solar Energy Materials and Solar Cells, 174, 370-379.

Senanayak, S. P., Ashar, A., Kanimozhi, C., Patil, S., \& Narayan, K. (2015). Room-temperature bandlike transport and Hall effect in a high-mobility ambipolar polymer. Physical Review B, 91(11), 115302.

Van Berkel, C., \& Powell, M. (1987). Resolution of amorphous silicon thin-film transistor instability mechanisms using ambipolar transistors. Applied Physics Letters, 51(14), 10941096.

Wang, Z., Li, Q., Chen, Y., Cui, B., Li, Y., Besenbacher, F., \& Dong, M. (2018). The ambipolar transport behavior of WSe 2 transistors and its analogue circuits. NPG Asia Materials, 10(8), 703-712.

Wannebroucq, A., Ouedraogo, S., Meunier-Prest, R., Suisse, J.-M., Bayo, M., \& Bouvet, M. (2018). On the interest of ambipolar materials for gas sensing. Sensors and Actuators B: Chemical, 258, 657-664.

Zhang, Y., Yao, Y., Sendeku, M. G., Yin, L., Zhan, X., Wang, F., He, J. (2019). Recent progress in CVD growth of 2D transition metal dichalcogenides and related heterostructures. Advanced materials, 31(41), 1901694.

Zhang, Y., Zhang, Y., Ji, Q., Ju, J., Yuan, H., Shi, J., Chen, Y. (2013). Controlled growth of high-quality monolayer WS2 layers on sapphire and imaging its grain boundary. Acs Nano, 7(10), 8963-8971. 